\title{
Heart Rate Assessment during Neonatal Resuscitation
}

\author{
Peter A. Johnson ${ }^{1,2}$ and Georg M. Schmölzer ${ }^{1,2, *(1)}$ \\ 1 Centre for the Studies of Asphyxia and Resuscitation, Neonatal Research Unit, Royal Alexandra Hospital, \\ Edmonton, AB T5A 0A1, Canada; paj1@ualberta.ca \\ 2 Department of Pediatrics, University of Alberta, Edmonton, AB T5A 0A1, Canada \\ * Correspondence: georg.schmoelzer@me.com; Tel.: +1-780-735-4660
}

Received: 10 January 2020; Accepted: 19 February 2020; Published: 23 February 2020

\begin{abstract}
Approximately 10\% of newborn infants require some form of respiratory support to successfully complete the fetal-to-neonatal transition. Heart rate (HR) determination is essential at birth to assess a newborn's wellbeing. Not only is it the most sensitive indicator to guide interventions during neonatal resuscitation, it is also valuable for assessing the infant's clinical status. As such, HR assessment is a key step at birth and throughout resuscitation, according to recommendations by the Neonatal Resuscitation Program algorithm. It is essential that HR is accurate, reliable, and fast to ensure interventions are delivered without delay and not prolonged. Ineffective HR assessment significantly increases the risk of hypoxic injury and infant mortality. The aims of this review are to summarize current practice, recommended techniques, novel technologies, and considerations for HR assessment during neonatal resuscitation at birth.
\end{abstract}

Keywords: infants; newborn; neonatal resuscitation; heart rate

\section{Introduction}

The transition from intrauterine to extrauterine life relies on major physiological changes at birth $[1,2]$. These changes include clearing of liquid from the lung to allow entry of air into distal gas-exchange regions, relaxation of the pulmonary vascular bed to increase pulmonary blood flow, increases in systemic vascular resistance, cessation of umbilical venous return, occlusion of the fetal shunts, and oxygen saturation, and increases in heart rate (HR) [1,3]. Although most infants make this transition from placental to pulmonary gas exchange at birth without help, $10 \%$ of newborn infants require positive pressure ventilation (PPV) assistance and $\sim 1 \%$ of these infants require advanced resuscitative interventions including chest compressions and medications [2].

International neonatal guidelines including the Neonatal Resuscitation Program (NRP) use predefined HR targets of 100 and 60 beats per minute (bpm) to initiate PPV and chest compressions, respectively $[1,2,4]$. These cutoffs are chosen arbitrarily, as neither human nor animal data are available to support these cutoffs [5]. Published normograms have reported the median HR at 1 minute can be $<100 \mathrm{bpm}$ in newborn infants that do not require any medical intervention [6]. At 2 minutes of age, HR increases to $>100 \mathrm{bpm}$, with the increase in HR being slower in preterm infants and infants born by caesarian section [6]. Ultimately, it is crucial to recognize the successfulness of resuscitations rely largely on how effectively and rapidly the appropriate interventions are delivered based on changes in $\mathrm{HR}$, as opposed to responding according to pre-established cutoffs.

Espinoza et al. used a post-transition asphyxia-induced bradycardia term piglet model and observed an increase in HR $>100 \mathrm{bpm}$ in only 6/30 (20\%) piglets after $30 \mathrm{~s}$ of adequate PPV [7]. The current NRP recommendation contrasts this observation, stating that $15 \mathrm{~s}$ of PPV at birth should result in an increase in HR [4]. In term apneic newborn infants, an adequate tidal volume will result in increased HR [8]. A similar relationship was observed in preterm infants during PPV and during 
sustained inflation [9-12]. Furthermore, in infants $<30$ weeks' gestation, an increase in HR $>100$ bpm required a median (IQR) times of 73 (24-165) s of PPV [13]. Additionally, HR only stabilized once HR was $>120$ bpm, requiring a longer median (IQR) time of 243 (191-351) s of PPV [13]. For infants $>34$ weeks gestation, it was determined that a decrease in HR to $<100 \mathrm{bpm}$ from a pause in PPV results in a 2 -fold increase in the risk of death, whereas an increase to $>100 \mathrm{bpm}$ during the initial treatment improves survival by $75 \%$ [14].

Therefore, if HR is detected too slowly or inaccurately, it will delay critical interventions or lead to inappropriate interventions, which are ineffective to improve the infant's status and/or increase the risk of cardiac arrest.

Current NRP guidelines recommend the use of umbilical cord palpation, auscultation, pulse oximetry (PO), and electrocardiography (ECG) for HR assessment during neonatal resuscitation at birth $[1,2,4,15]$. However, there have been some concerns about their accuracy, latency or feasibility for clinical assessment [16-20]. Below, we discuss recommended HR assessment approaches, their outcomes, and ongoing challenges (Table 1).

Table 1. Recommended techniques for heart rate assessment, associated outcomes including accuracy, time required for assessment, and reliability of technique, and limitations. Abbreviations: HR: heart rate; PO: pulse oximetry ECG: electrocardiography; bpm: beats per minute; sec: seconds.

\begin{tabular}{|c|c|c|c|c|}
\hline $\begin{array}{l}\text { HR Assessment } \\
\text { Technique }\end{array}$ & Palpation & Auscultation & PO & ECG \\
\hline Accuracy & $\begin{array}{l}\text { Underestimates HR } \\
>100 \mathrm{bpm} \text {, fairly } \\
\text { accurate }<100 \mathrm{bpm} \\
\text { - Underestimates } \\
21 \mathrm{bpm}, \text { compared } \\
\text { to ECG }\end{array}$ & $\begin{array}{l}\text { Underestimates HR } \\
>100 \mathrm{bpm} \text {, fairly } \\
\text { accurate }<100 \mathrm{bpm} \\
\text { One study suggests } \\
\text { healthcare providers } \\
\text { overestimate HR } \\
<60 \mathrm{bpm}\end{array}$ & $\begin{array}{l}\text { Accurate, but } \\
\text { underestimates HR } \\
\text { in the first minutes } \\
\text { of life }(\sim 2 \mathrm{~min})\end{array}$ & "Gold standard" \\
\hline $\begin{array}{l}\text { Time required for } \\
\text { assessment }\end{array}$ & $\sim 7-19 \mathrm{sec}$ & $\sim 7-19 \mathrm{sec}$ & $\sim 60-120 \mathrm{sec}$ & $\sim 30-60 \mathrm{sec}$ \\
\hline $\begin{array}{l}\text { Method to confirm } \\
\text { reliability }\end{array}$ & Feeling pulse & Hearing heartbeats & $\begin{array}{l}\text { Observing a regular } \\
\text { waves on the PO } \\
\text { waveform }\end{array}$ & $\begin{array}{l}\text { Observing regular QRS } \\
\text { complexes on ECG } \\
\text { waveform }\end{array}$ \\
\hline
\end{tabular}

\section{Auscultation/Palpation}

Palpation involves the assessment of a pulse at the umbilical, femoral, or brachial arteries, whereas auscultation involves using a stethoscope to listen to heart beats, normally from the chest of the infant $[20,21]$. The NRP recommends counting the heart beats heard over $6 \mathrm{~s}$ and multiplying by 10 to determine HR in bpm [22]. Accounting for placement, pulse detection, listening window of 6 $\mathrm{s}$, and time required for mental computation, this technique allows for quick approximation of HR. A total HR assessment time ranging from 7-19 s on average have been previously reported for both palpation and auscultation $[16,23,24]$.

Owen \& Wyllie compared palpation at the femoral and brachial artery and umbilical cord in newborn infants to assess the accuracy of calculating a HR $>100 \mathrm{bpm}$ [21]. Auscultation using a 
stethoscope provided HR > $100 \mathrm{bpm}$ in $100 \%$ of the cases, whereas palpation did not always result in a palpable HR [21]. Palpation of the umbilical pulse was accurate for $55 \%$ of cases, compared to $20 \%$ and $25 \%$ at femoral and brachial pulse, respectively [21]. Moreover, a concerning 25\% and $60 \%$ of participants were unable to palpate a pulse, while $15 \%$ and $45 \%$ incorrectly assessed $\mathrm{HR}$ as $<100 \mathrm{bpm}$ using the femoral and brachial pulse, respectively [21]. Therefore, auscultation is more accurate than palpating from any of the three locations, but when a stethoscope is not available, palpation of the umbilical cord provides greater accuracy.

Chitkara et al. and Boon et al. randomized healthcare providers to either auscultation or palpation, blinding them to high-fidelity simulated neonatal resuscitation scenarios [22,25]. Healthcare providers were randomized to scenarios representing the NRP HR target ranges at $>100,60-100,<60$ bpm and required to perform an initial assessment followed by subsequent assessments. Both studies reported the greatest accuracy of $\mathrm{HR}$ at $<60 \mathrm{bpm}$, followed by 60-100 bpm, and then $>100 \mathrm{bpm}[22,25]$. Chitkara et al. additionally determined no difference between initial and subsequent assessments, with errors occurring an alarming $26-48 \%$ and $26-52 \%$ of the time, respectively. However, a more recent simulation study by Money et al. evaluated the accuracy of auscultation according to NRP HR target ranges and identified overestimation of $\mathrm{HR}<60 \mathrm{bpm}$ and underestimation of $\mathrm{HR}>100 \mathrm{bpm}$ as a common tendency for participants [26]. The latter observation was similar to a study by Kamlin et al., who compared auscultation and umbilical cord palpation with ECG in term newborn infants and reported both auscultation and umbilical cord palpation underestimated HR with a mean HR difference of 14 and $21 \mathrm{bpm}$, compared to ECG [27]. These studies suggest HR assessment using palpation or auscultation are inaccurate, thereby resulting in a greater number of incorrect assessments for determining HR at birth. This is concerning, as under- or overestimation of HR can result in inappropriate management (i.e., early or delayed interventions) in $28 \%$ of cases in a simulated environment alone [16]. During neonatal resuscitation in the delivery room, assessment of HR using auscultation remains challenging. Resuscitators need to assess HR while working under high stress levels, high cognitive load, and varying surrounding noise levels. They further have to pay attention and focus on the task, which is of particular importance within the first few minutes after birth as a wide HR variability might occur and those responses are unpredictable compared to manikins.

\section{Pulse Oximetry}

$\mathrm{PO}$ can provide a continuous and simultaneous measure of $\mathrm{SpO}_{2}$ and $\mathrm{HR}$ from the infants hand, wrist, or foot $[28,29]$. It functions by using two light diodes, which emit light at red and infrared frequencies, and a photo-detector that measures changes in the transmitted light from the oxygenated and deoxygenated blood to determine oxygen saturation [30]. HR can be determined using the light intensity changes, which corresponds to pulsatile blood volume changes in the artery [30]. International guidelines recommend the use of PO during PPV or when providing supplemental oxygen [1,2]. However, there are several limitations of PO to monitor HR including (i) delays in time needed to display first HR values [31,32], (ii) potential underestimation of HR compared to ECG outcomes [19], and (iii) difficulties in obtaining a good signal quality when $\mathrm{HR}<100 \mathrm{bpm}$ [19,31]. Other limitations include: low peripheral perfusion, the effect of transitional circulation, low volume state, vernix effects, skin oedema, acrocyanosis, signal dropout, movement artefacts, arrhythmias, and presence of ambient lighting, which might delay or interfere with PO HR measurements [33-37].

The vast majority of studies examining the accuracy and reliability of PO for HR assessment utilize ECG for comparison [15]. We have identified six studies comparing PO to ECG for HR assessment in the delivery room $[19,23,31,32,38,39]$ and one in the neonatal intensive care unit (NICU) [40]. While accuracy is most commonly described as the level of association with the gold standard (ECG for most cases), reliability is defined by detection and signal quality of a waveform (PO or ECG). Kamlin et al. analyzed 5877 data pairs of ECG HR and good-quality PO HR (defined by the presence of signal bars and no "low-signal quality" message) in 55 preterm or term infants reporting a mean (2 SD) difference between ECG HR and PO HR as -2 (26) bpm overall and -0.5 (16) bpm in infants 
who received either positive-pressure ventilation and/or cardiac massage [31]. However, at ECG $\mathrm{HR}<100 \mathrm{bpm}$, good-quality PO HR $<100 \mathrm{bpm}$ could only be detected $89 \%$ of the time [31]. While these former results suggest a strong accuracy for PO HR monitoring at birth when compared to ECG HR monitoring, the latter suggests the need to explore specific outcomes during bradycardia. In a study by Iglesias et al., both PO and ECG were used to detect bradycardia (HR $<100 \mathrm{bpm})$ during stabilization [38]. PO detects both the start and end of bradycardia episodes a median time of 5 seconds slower than ECG [38], which is concerning as it could lead to delayed initiation of resuscitation interventions or the unnecessary prolongation of interventions. A study by van Vonderen et al. examined the accuracy of PO, compared to ECG, for HR assessment in the first minutes after birth [19]. PO underestimated HR, displaying HR $<100 \mathrm{bpm}$ and suggesting bradycardia in the first minutes after birth in uncompromised infants [19]. This underestimation was verified by the weaker association of PO HR with left ventricular outflow when compared to ECG HR, which suggests PO missed beats and is unreliable for detecting all pulse waves from the peripheral vasculature in the immediate transition [19]. With the low accuracy and reliability of PO during the first minutes of life, including the Golden Minute when HR assessments are strongly recommended, the latency of signal detection must be a major consideration for HR assessment at birth.

Unfortunately, long latency ranging from 1-2 min for sensor attachment and reliable signal display following birth are reported for PO, indicating HR is not detected within the Golden Minute [15,41]. In a study by Mizumoto et al., achieving a reliable PO and ECG signal at birth required a median (IQR) time of 122 (101-146) vs. 38 (34-43) s, respectively [32]. Furthermore, HR detection was more difficult using PO when compared to ECG, in bradycardic newborn infants with poor perfusion [32]. Therefore, healthcare providers must not rely exclusively on PO, especially during bradycardia, as PO might underestimate HR. Two further studies have examined the fastest approach to detect HR using two different PO application techniques [18,42]. One technique involves attaching the PO sensor to the oximeter first (STOF), whereas the other requires the attachment of the sensor to the infant first (STIF). While the first study determined the STIF method was faster and more reliable providing data within $90 \mathrm{~s}$ after birth [18], the second showed suggested STOF had a faster signal acquisition time, although both techniques provided a similar time from birth to a reliable signal [37]. In spite of these limitations, PO is valuable for HR assessment in various special cases in the delivery room where ECG may not be effective.

\section{Electrocardiography}

ECGs used for neonatal resuscitation utilizes three-electrode ECGs, which typically involves the placement of these electrodes on right arm, left arm and left leg or abdomen [42]. Electrical activity originating from the sinoatrial node of the heart is recorded by these electrodes and used to generate a continuous ECG waveform. As ECGs utilize R-wave detector algorithms using the QRS segment for calculation of HR, continuous ECG waveforms containing the QRS complex can be utilized to confirm the reliability of the signal [42,43]. ECG is currently considered the "gold standard" for HR measurements, which has been demonstrated to be accurate and reliable in displaying HR compared to the above mentioned recommended techniques [1,44].

We have identified three randomized clinical trials assessing latency, reliability or neonatal resuscitation outcomes when using ECG for HR assessment through a systematic review [13,20,36,37]. While Murphy et al. performed two trials in low-risk infants [23,39], Katheria et al. conducted a trial in preterm infants during stabilization at birth [40]. All studies involved blinding and randomized allocation of the infants into a PO or ECG group. Moreover, all studies reported a faster median (IQR) time for HR assessment using ECG compared to PO at birth [24 (19-39) s versus 48 (36-69) s and 66 (46-86) s versus 114 (75-153) s]. This suggests that HR detection during the Golden Minute may or may not be achieved by ECG. In a recent study by Gulati et al., a novel technique has been suggested to overcome this delay by pre-setting ECG electrodes on the bed for attachment to the infants back, while 
also allowing for chest compressions not to interfere with ECG signals [45]. However, this technique has yet to be evaluated in infants requiring resuscitation.

Additionally, Murphy et al. determined auscultation and PO underestimated ECG HR by a mean difference ( $95 \%$ confidence interval) of $-9(-15$ to -2$)$ and -5 ( -12 to 2$) \mathrm{bpm}$, respectively [23]. This supports previous studies, which identified the other techniques underestimate ECG HR for infants with HR $>100 \mathrm{bpm}$. In the trial by Katheria et al., it was determined PO HR was lower than ECG HR in the first two minutes of life, yet no significant differences were determined in time to the delivery of the appropriate interventions in both groups [40]. While this is encouraging, this initial underestimation may be more critical in high-risk infants that require advanced interventions such as chest compression. In fact, a recent retrospective study suggests ECG use is associated with increasing administration of chest compressions and fewer endotracheal intubations in the delivery room [46]. Another benefit of having an early, reliable HR is the improved preparedness of the clinical team for any intervention.

Despite this efficacy, the use of ECG also has several limitations including (i) time needed to clean newborns' skin (e.g., from blood, vernix, mucus or amniotic fluid), (ii) potential signal interference from suboptimal placed ECG-lead (due to aforementioned fluids), (iii) potential damage and risk of infection caused by the leads on the delicate skin of premature infants, and (iv) or special clinical cases involving hydrops fetalis [17] or pulseless electric activity (PEA) which could result in misinterpretation of displayed ECG HR [24,42,47].

\section{Pulseless Electrical Activity}

PEA is a phenomenon that occurs when cardiac output is zero but the ECG still displays an HR. PEA involves cardiac electrical activity in the absence of a detectable pulse and has been reported in adults and children, most commonly after hypoxia, severe volume loss, sepsis, tension pneumothorax or following cardiac arrest [7]. There is increasing evidence that PEA occurs in the delivery room [15]. Two studies report that the ECG displayed a HR during PEA in $40-50 \%$ of asphyxiated newborn piglets $[48,49]$. There have been one case report and a case series totaling seven cases of PEA in the delivery room during neonatal resuscitation [50-53]. This is concerning, especially if healthcare professionals are relying exclusively on the ECG signal. For current practice, we therefore recommend assessments using a combination of current recommendations: palpation, auscultation, PO and ECG, in light of these cases.

\section{Novel Technologies}

There are several emerging HR assessment technologies, which have been recently summarized in There are several emerging HR assessment technologies, which have been summarized over the recent years in three systematic reviews (Table 2; Figure 1A,B) [15,41,54]. These novel technologies can be classified as contact (i.e., ECG, PO, dry-electrode ECG, electrical velocimetry, reflectance photoplethysmography, electromyography), intermittent contact (i.e., auscultation/palpation, Doppler ultrasound, digital stethoscope), non-contact or sensor-based (i.e., camera-based photoplethysmography, capacitive sensors, piezoelectric sensors, laser Doppler vibrometry), and assistive technologies (i.e., tap-based smartphone apps). While contact technologies require continuous contact with the infant and may be adverse for the fragile, premature infant skin, intermittent contact is less intrusive whereas non-contact methods are the least intrusive. Updates to existing techniques, such as the use of the digital stethoscope and smartphone apps to enhance accuracy and time required for auscultation [15], and application of electrodes on the infant's back for improved ECG latency and reliability during resuscitation, have also been identified. While these technologies are promising, further evaluation is needed before they can be translated into routine use. 
Table 2. Novel technologies or techniques for heart rate assessment identified in this review and three systematic reviews $[15,41,54]$. Each technology is characterized according to its classification, functionalities and strengths, and limitations. Abbreviations: HR: heart rate; ECG: electrocardiography; PO: pulse oximetry; PPG: photoplethysmography; EMG: electromyography; cPPG: camera-based photoplethysmography; STIF: sensor to infant first method; STOF: sensor to oximeter first method; sec: second.

\begin{tabular}{|c|c|c|c|}
\hline $\begin{array}{l}\text { Novel Technology/ } \\
\text { Technique }\end{array}$ & Classification & Description & Limitations \\
\hline ECG presetting & Contact & $\begin{array}{l}\text { ECG sensors can be preset in a triangle } \\
\text { formation facing up on the bed easier \& } \\
\text { faster HR detection upon delivery \& ease of } \\
\text { access during chest compressions. }\end{array}$ & $\begin{array}{l}\text { HR signal loss is more frequent } \\
\text { than conventional method. }\end{array}$ \\
\hline $\begin{array}{l}\text { PO sensor application } \\
\text { techniques }\end{array}$ & Contact & $\begin{array}{l}\text { Either STIF or STOF methods may result in } \\
\text { faster HR detection time. Studies report } \\
\text { similar reliability for both techniques. }\end{array}$ & $\begin{array}{l}\text { Uncertainty which technique } \\
\text { is faster at birth. }\end{array}$ \\
\hline Dry-electrode ECG & Contact & $\begin{array}{l}\text { Uses dry-electrodes to detect reliable HR } \\
\text { with short latency (within } \sim 7-8 \mathrm{sec} \text { ) }\end{array}$ & $\begin{array}{l}\text { Requires drying infant prior to } \\
\text { use \& movement } \\
\text { causes interference. }\end{array}$ \\
\hline Electrical velocimetry & Contact & $\begin{array}{l}\text { Uses blood conductivity to measure cardiac } \\
\text { output, stroke volume, \& HR, providing } \\
\text { accurate HR compared to ECG. }\end{array}$ & $\begin{array}{l}\text { Only assessed in term infants } \\
\text { before \& movement } \\
\text { causes interference. }\end{array}$ \\
\hline Reflectance PPG/PO & Contact & $\begin{array}{l}\text { Uses reflectance instead of transmission to } \\
\text { monitor } \mathrm{SpO}_{2} \& \mathrm{HR} \text {, providing } \\
\text { accurate } \mathrm{HR} \text {. }\end{array}$ & Similar limitations to PO. \\
\hline Transcutaneous EMG & Contact & $\begin{array}{l}\text { Uses electrical activity of muscle tissue \& } \\
\text { has a high degree of accuracy compared } \\
\text { to ECG }\end{array}$ & $\begin{array}{l}\text { Similar to ECG and have } \\
\text { limited advantages over it. }\end{array}$ \\
\hline Doppler ultrasound & $\begin{array}{l}\text { Contact, intermittent } \\
\text { contact }\end{array}$ & $\begin{array}{l}\text { Uses ultrasound frequency sound waves to } \\
\text { detect HR accurately \& within a short } \\
\text { period of time. }\end{array}$ & $\begin{array}{l}\text { Movement can affect skin-gel } \\
\text { interface, while noise \& } \\
\text { ventilation can interfere with } \\
\text { audible \& visual signal, } \\
\text { respectively. }\end{array}$ \\
\hline Digital stethoscope & Intermittent contact & $\begin{array}{l}\text { Uses electronics to augment sound detected } \\
\text { by auscultation with greater clarity to } \\
\text { improve HR accuracy. }\end{array}$ & $\begin{array}{l}\text { Influenced by movement \& } \\
\text { noise \& has similar limitations } \\
\text { to auscultation. }\end{array}$ \\
\hline cPPG & Non-contact & $\begin{array}{l}\text { Uses changes in wavelengths over a region } \\
\text { of interest to determine HR, offering a high } \\
\text { degree of accuracy to ECG. }\end{array}$ & $\begin{array}{l}\text { Signal loss is common about } \\
20 \% \text { of the time due to } \\
\text { ambient light, movement, } \\
\text { \& obstructions. }\end{array}$ \\
\hline Capacitive sensors & $\begin{array}{l}\text { Non-contact, } \\
\text { sensor-based }\end{array}$ & $\begin{array}{l}\text { Forms a capacitive electrode between the } \\
\text { infants' skin \& an electrode without directly } \\
\text { touching the infant to determine an } \\
\text { accurate ECG signal. }\end{array}$ & $\begin{array}{l}\text { Signal loss is common about } \\
15 \% \text { of the time due to } \\
\text { movement, etc. }\end{array}$ \\
\hline Piezoelectric sensors & $\begin{array}{l}\text { Non-contact, } \\
\text { sensor-based }\end{array}$ & $\begin{array}{l}\text { Uses acoustic vibrations from heartbeats to } \\
\text { produce electrical signals providing HR, } \\
\text { offering accurate data compared to ECG. }\end{array}$ & $\begin{array}{l}\text { Movement from ventilation, } \\
\text { infant movement, or } \\
\text { resuscitator movement greatly } \\
\text { affects signals. }\end{array}$ \\
\hline Laser Doppler & Non-contact & $\begin{array}{l}\text { Uses a laser beam to detect movements in } \\
\text { thoracic walls of infant due to cardiac } \\
\text { activity, providing a fairly accurate HR } \\
\text { compared to ECG. }\end{array}$ & $\begin{array}{l}\text { There is uncertainty as well as } \\
\text { a high cost \& complexity } \\
\text { associated with the system. }\end{array}$ \\
\hline $\begin{array}{l}\text { Tap-based } \\
\text { smartphone apps }\end{array}$ & Assistive & $\begin{array}{l}\text { Uses screen tapping, which is paired with } \\
\text { auscultation to detect HR based on timing } \\
\text { between heartbeats and provides a fast and } \\
\text { accurate HR in simulation scenarios. Also } \\
\text { useful and accessible in } \\
\text { low-resource settings. }\end{array}$ & $\begin{array}{l}\text { Technical software problems, } \\
\text { risk of infection with } \\
\text { smartphone use, requires } \\
\text { auscultation \& therefore has } \\
\text { the same limitations }\end{array}$ \\
\hline
\end{tabular}




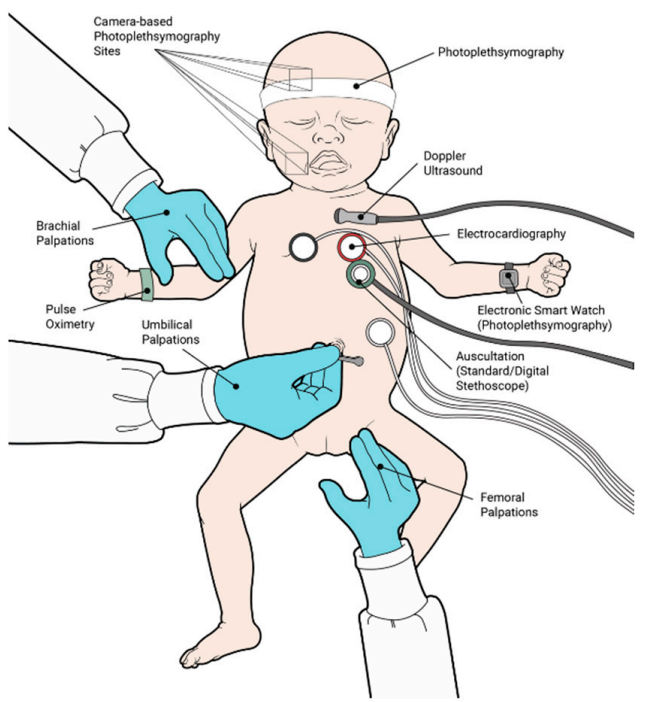

(A)

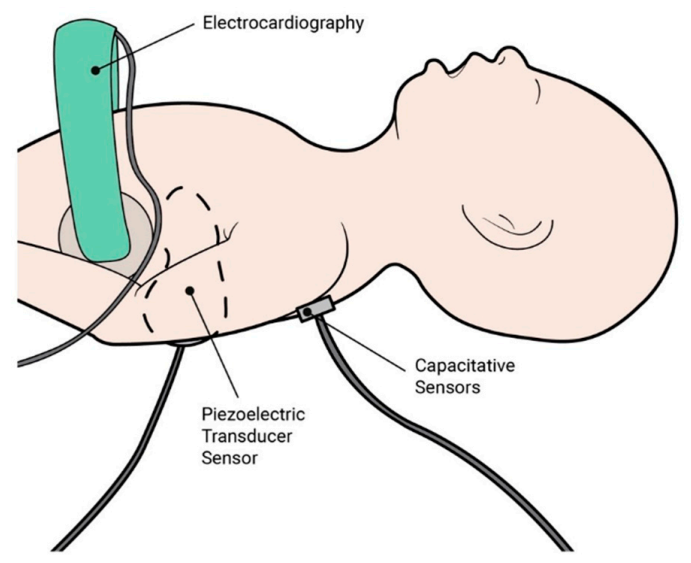

(B)

Figure 1. Current and novel technologies or techniques for heart rate assessment identified by Johnson et al. [15]. (A): An illustration of current recommendations, including electrocardiography, pulse oximetry, auscultation with a standard stethoscope, and palpation from brachial, femoral, and umbilical arteries, and novel technologies, including auscultation with a digital stethoscope, Doppler ultrasound, photoplethysmography, camera-based photoplethysmography for heart rate assessment. (B): An illustration of novel technologies including dry-electrode electrocardiography, and two sensor-based methods for heart rate assessment. Reproduced with permission from RETAIN Labs Medical Inc. (https://www.playretain.com).

\section{Low Resource Settings}

Despite international guidelines, there exist several differences in neonatal resuscitation practices at birth in different regions around the world. Technologies such as ECG and PO are costly and inaccessible in low-resource settings. In these settings, auscultation and palpation are most suitable and often the only approach. While it is possible to obtain continuous HR data by dedicating one member of the clinical team to continuous HR assessment via auscultation or palpation, this places a higher demand on the number of members required on the team [55]. In addition to environmental factors such as the availability of resources, the availability of clinical staff, their levels of training, and competency of healthcare professionals may also influence the success of the resuscitation.

\section{Conclusions}

Heart rate assessment is vital at birth to guide neonatal resuscitation. However, current neonatal resuscitation guidelines recommend the use of auscultation/palpation, pulse oximetry, and electrocardiography for heart rate assessment. While auscultation/palpation are fast and reliable, they are inaccurate in some instances. Pulse oximetry and electrocardiography are superior in accuracy compared to auscultation/palpation, however they require a longer time to assess the initial heart rate.

Author Contributions: Conception and design: G.M.S., P.A.J.; Literature search: G.M.S., P.A.J.; Drafting of the article: G.M.S., P.A.J.; Critical revision of the article for important intellectual content: G.M.S., P.A.J.; Final approval of the article: G.M.S., P.A.J. All authors have read and agreed to the published version of the manuscript.

Funding: We would like to thank the public for donating money to our funding agencies: P.A.J. is a recipient of the University of Alberta Medical Sciences Graduate Program Scholarship and the Women and Children's Health Research Institute Graduate Studentship. G.M.S. is a recipient of the Heart and Stroke Foundation/University of Alberta Professorship of Neonatal Resuscitation, a National New Investigator of the Heart and Stroke Foundation Canada and an Alberta New Investigator of the Heart and Stroke Foundation Alberta.

Conflicts of Interest: The authors declare no conflict of interest. 


\section{Abbreviations}

$\begin{array}{ll}\text { HR } & \text { Heart rate } \\ \text { NRP } & \text { Neonatal Resuscitation Program } \\ \text { NICU } & \text { Neonatal intensive care unit } \\ \text { PPV } & \text { Positive pressure ventilation } \\ \text { bpm } & \text { Beats per minute } \\ \mathrm{SpO}_{2} & \text { Oxygen saturation } \\ \mathrm{PO} & \text { Pulse oximetry } \\ \mathrm{ECG} & \text { Electrocardiography } \\ \mathrm{PEA} & \text { Pulseless electric activity } \\ \mathrm{CI} & \text { Confidence interval } \\ \mathrm{SD} & \text { Standard deviation } \\ \mathrm{IQR} & \text { Interquartile range }\end{array}$

\section{References}

1. Perlman, J.; Wyllie, J.; Kattwinkel, J.; Wyckoff, M.; Aziz, K.; Guinsburg, R.; Kim, H.; Hg, L.; Mildenhall, L.; Simon, W.; et al. Part 7: Neonatal Resuscitation 2015 International Consensus on Cardiopulmonary Resuscitation and Emergency Cardiovascular Care Science With Treatment Recommendations. Circulation 2015, 132, S204-S241. [CrossRef]

2. Wyckoff, M.H.; Aziz, K.; Escobedo, M.B.; Kapadia, V.S.; Kattwinkel, J.; Perlman, J.M.; Simon, W.M.; Weiner, G.M.; Zaichkin, J.G. Part 13: Neonatal Resuscitation. Circulation 2015, 132, S543-S560. [CrossRef] [PubMed]

3. Siew, M.L.; Kitchen, M.J.; te Pas, A.B.; Harding, R.; Hooper, S.B. Pulmonary Transition at Birth. In The Lung; Elsevier: Amsterdam, The Netherlands, 2014; pp. 251-264.

4. Weiner, G.M.; Zaichkin, J.; Kattwinkel, J.; Ades, A. Textbook of Neonatal Resuscitation, 7th ed.; Weiner, G.M., Zaichkin, J., Kattwinkel, J., Ades, A., Eds.; American Academy of Pediatrics: Elk Grove Village, IL, USA, 2016; ISBN 9781610020251.

5. Saugstad, O.D. New guidelines for newborn resuscitation-A critical evaluation. Acta Paediatr. Int. J. Paediatr. 2011, 100, 1058-1062. [CrossRef] [PubMed]

6. Dawson, J.A.; Kamlin, C.O.F.; Wong, C.; te Pas, A.B.; Vento, M.; Cole, T.J.; Donath, S.M.; Hooper, S.B.; Davis, P.G.; Morley, C.J. Changes in heart rate in the first minutes after birth. Arch. Dis. Child.-Fetal Neonatal Ed. 2010, 95, F177-F181. [CrossRef] [PubMed]

7. Espinoza, M.L.; Cheung, P.Y.; Lee, T.F.; O’Reilly, M.; Schmölzer, G.M. Heart rate changes during positive pressure ventilation after asphyxia-induced bradycardia in a porcine model of neonatal resuscitation. Arch. Dis. Child.-Fetal Neonatal Ed. 2019, 104, F98-F101. [CrossRef]

8. Linde, J.E.; Schulz, J.; Perlman, J.M.; Øymar, K.; Blacy, L.; Kidanto, H.; Ersdal, H.L. The relation between given volume and heart rate during newborn resuscitation. Resuscitation 2017, 117, 80-86. [CrossRef]

9. Schmölzer, G.M.; Dawson, J.A.; Kamlin, C.O.F.; O’Donnell, C.P.F.; Morley, C.J.; Davis, P.G. Airway obstruction and gas leak during mask ventilation of preterm infants in the delivery room. Arch. Dis. Child.-Fetal Neonatal Ed. 2011, 96, F254-F257. [CrossRef]

10. Palme-Kilander, C.; Tunell, R.; Chiwei, Y. Pulmonary gas exchange immediately after birth in spontaneously breathing infants. Arch. Dis. Child. 1993, 68, 6-10. [CrossRef]

11. Pichler, G.; Schmölzer, G.M.; Urlesberger, B. Cerebral tissue oxygenation during immediate neonatal transition and resuscitation. Front. Pediatr. 2017, 5, 29. [CrossRef]

12. Fuchs, H. German experience in the management of ELGAN infants. Acta Biomed. 2015, 86, 16-20.

13. Yam, C.H.; Dawson, J.A.; Schmölzer, G.M.; Morley, C.J.; Davis, P.G. Heart rate changes during resuscitation of newly born infants. Arch. Dis. Child.-Fetal Neonatal Ed. 2011, 96, F102-F107. [CrossRef] [PubMed]

14. Linde, J.E.; Perlman, J.M.; Øymar, K.; Schulz, J.; Eilevstjønn, J.; Thallinger, M.; Kusulla, S.; Kidanto, H.L.; Ersdal, H.L. Predictors of 24-h outcome in newborns in need of positive pressure ventilation at birth. Resuscitation 2018, 129, 1-5. [CrossRef] [PubMed] 
15. Johnson, P.A.; Cheung, P.-Y.; Lee, T.-F.; O’Reilly, M.; Schmölzer, G.M. Novel technologies for heart rate assessment during neonatal resuscitation at birth—A systematic review. Resuscitation 2019, 143, $196-207$. [CrossRef] [PubMed]

16. Voogdt, K.G.J.A.; Morrison, A.C.; Wood, F.E.; Van Elburg, R.M.; Wyllie, J.P. A randomised, simulated study assessing auscultation of heart rate at birth. Resuscitation 2010, 81, 1000-1003. [CrossRef]

17. Hodgson, K.A.; Kamlin, C.O.F.; Rogerson, S.; Thio, M. ECG monitoring in the delivery room is not reliable for all patients. Arch. Dis. Child.-Fetal Neonatal Ed. 2018, 103, F88. [CrossRef]

18. O’Donnell, C.P.F.; Omar, C.; Kamlin, F.; Davis, P.G.; Morley, C.J. Feasibility of and delay in obtaining pulse oximetry during neonatal resuscitation. J. Pediatr. 2005, 147, 698-699. [CrossRef]

19. Van Vonderen, J.J.; Hooper, S.B.; Kroese, J.K.; Roest, A.A.W.; Narayen, I.C.; Van Zwet, E.W.; Te Pas, A.B. Pulse oximetry measures a lower heart rate at birth compared with electrocardiography. J. Pediatr. 2015, 166, 49-53. [CrossRef]

20. Wyckoff, M.; Aziz, K.; Escobedo, M.; Kapadia, V.; Kattwinkel, J.; Perlman, J.; Simon, W.; Weiner, G.; Zaichkin, J. Part 13: Neonatal Resuscitation 2015 American Heart Association Guidelines Update for Cardiopulmonary Resuscitation and Emergency Cardiovascular Care. Pediatrics 2015, 136, 196-218. [CrossRef]

21. Owen, C.J.; Wyllie, J.P. Determination of heart rate in the baby at birth. Resuscitation 2004, 60, $213-217$. [CrossRef]

22. Boon, W.; McAllister, J.; Attar, M.A.; Chapman, R.L.; Mullan, P.B.; Haftel, H.M. Evaluation of Heart Rate Assessment Timing, Communication, Accuracy, and Clinical Decision-Making during High Fidelity Simulation of Neonatal Resuscitation. Int. J. Pediatr. 2014, 2014, 927430. [CrossRef]

23. Murphy, M.C.; De Angelis, L.; McCarthy, L.K.; O’Donnell, C.P.F. Comparison of infant heart rate assessment by auscultation, ECG and oximetry in the delivery room. Arch. Dis. Child.-Fetal Neonatal Ed. 2018, 103, F490-F492. [CrossRef] [PubMed]

24. Höök, S.M.; Pejovic, N.J.; Marrone, G.; Tyllesk, T.; Alfven, T. Accurate and fast neonatal heart rate assessment with a smartphone-based application-a manikin study. Acta Padiatr. 2018, 107, 1548-1554. [CrossRef] [PubMed]

25. Chitkara, R.; Rajani, A.K.; Oehlert, J.W.; Lee, H.C.; Epi, M.; Halamek, L.P. The accuracy of human senses in the detection of neonatal heart rate during standardized simulated resuscitation: Implications for delivery of care, training and technology design. Resuscitation. 2013, 84, 369-372. [CrossRef] [PubMed]

26. Money, N.; Kusheleva, N.; Ruano, S.; Demissie, S.; Blau, J.; Singhi, V. Who's counting? Assessing the effects of a simulation-based training intervention on the accuracy of neonatal heart rate auscultation. J. Perinatol. 2019, 39, 634-639. [CrossRef] [PubMed]

27. Kamlin, C.O.F.; O'donnell, C.P.F.; Everest, N.J.; Davis, P.G.; Morley, C.J. Accuracy of clinical assessment of infant heart rate in the delivery room. Resuscitation 2006, 71, 319-321. [CrossRef] [PubMed]

28. Dawson, J.A.; Omar Kamlin, C.F.; Vento, M.; Wong, C.; Cole, T.J.; Donath, S.M.; Davis, P.G.; Morley, C.J. Defining the Reference Range for Oxygen Saturation for Infants After Birth. Pediatrics 2010, 125, 1340-1347. [CrossRef]

29. Schmölzer, G.M.; Kamlin, O.C.; Dawson, J.A.; Te Pas, A.B.; Morley, C.J.; Davis, P.G. Respiratory monitoring of neonatal resuscitation. Arch. Dis. Child.-Fetal Neonatal Ed. 2010, 95, 295-303. [CrossRef]

30. Jahan, E.; Barua, T.; Salma, U. An overview on heart rate monitoring and pulse oximeter system. Int. J. Latest Res. Sci. Technol. 2014, 3, 148-152.

31. Kamlin, C.O.F.; Dawson, J.A.; O’Donnell, C.P.F.; Morley, C.J.; Donath, S.M.; Sekhon, J.; Davis, P.G. Accuracy of pulse oximetry measurement of heart rate of newborn infants in the delivery room. J. Pediatr. 2008, 152, 756-760. [CrossRef]

32. Mizumoto, H.; Tomotaki, S.; Shibata, H.; Ueda, K.; Akashi, R.; Uchio, H.; Hata, D. Electrocardiogram shows reliable heart rates much earlier than pulse oximetry during neonatal resuscitation. Pediatr. Int. 2012, 54, 205-207. [CrossRef]

33. Kopotic, R.J.; Lindner, W. Assessing high-risk infants in the delivery room with pulse oximetry. Anesth. Analg. 2002, 94, S31-S36. [PubMed]

34. Workie, F.A.; Rais-Bahrami, K.; Short, B.L. Clinical Use of New-Generation Pulse Oximeters in the Neonatal Intensive Care Unit. Am. J. Perinatol. 2005, 22, 357-360. [CrossRef] [PubMed]

35. Dawson, J.A.; Morley, C.J. Monitoring oxygen saturation and heart rate in the early neonatal period. Semin. Fetal Neonatal Med. 2010, 15, 203-207. [CrossRef] [PubMed] 
36. Masimo Corporation Radical. Signal Extraction Pulse Oximeter Operator's Manual; Masimo Corporation Radical: Irvine, CA, USA, 2006; pp. 1.1-8.2.

37. Louis, D.; Sundaram, V.; Kumar, P. Pulse Oximeter Sensor Application During Neonatal Resuscitation: A Randomized Controlled Trial. Pediatrics 2014, 133, 476-482. [CrossRef] [PubMed]

38. Iglesias, B.; Rodrí Guez, J.; Aleo, E.; Criado, E.; Martí Nez-Orgado, J.; Arruza, L.; Lagos, M. 3-lead electrocardiogram is more reliable than pulse oximetry to detect bradycardia during stabilisation at birth of very preterm infants. Arch. Dis. Child.-Fetal Neonatal Ed. 2018, 103, F233-F237. [CrossRef] [PubMed]

39. Murphy, M.C.; De Angelis, L.; Mccarthy, L.K.; O’Donnell, C.P.F.; Patrick, C.; O'donnell, F.; Finbarr O'donnell, P. Randomised study comparing heart rate measurement in newly born infants using a monitor incorporating electrocardiogram and pulse oximeter versus pulse oximeter alone. Arch. Dis. Child.-Fetal Neonatal Ed. 2018, 104, F547-F550. [CrossRef]

40. Katheria, A.; Arnell, K.; Brown, M.; Hassen, K.; Maldonado, M.; Rich, W.; Finer, N. A pilot randomized controlled trial of EKG for neonatal resuscitation. PLoS ONE 2017, 12, e0187730. [CrossRef]

41. Anton, O.; Fernandez, R.; Rendon-Morales, E.; Aviles-Espinosa, R.; Jordan, H.; Rabe, H. Heart rate monitoring in newborn babies: A systematic review. Neonatology 2019, 116, 199-210. [CrossRef]

42. Di Fiore, J.M. Neonatal cardiorespiratory monitoring techniques. Semin. Neonatol. 2004, 9, $195-203$. [CrossRef]

43. Hutchon, D.J.R. Technological Developments in Neonatal Care at Birth. J. Nurs. Care 2013, 3, 1000218. [CrossRef]

44. Katheria, A.; Rich, W.; Finer, N. Electrocardiogram Provides a Continuous Heart Rate Faster Than Oximetry During Neonatal Resuscitation. Pediatrics 2012, 130, e1177-e1181. [CrossRef] [PubMed]

45. Gulati, R.; Zayek, M.; Eyal, F. Presetting ECG electrodes for earlier heart rate detection in the delivery room. Resuscitation 2018, 128, 83-87. [CrossRef] [PubMed]

46. Shah, B.A.; Wlodaver, A.G.; Escobedo, M.B.; Ahmed, S.T.; Blunt, M.H.; Anderson, M.P.; Szyld, E.G. Impact of electronic cardiac (ECG) monitoring on delivery room resuscitation and neonatal outcomes. Resuscitation 2019, 143, 10-16. [CrossRef]

47. Phillipos, E.; Solevåg, A.L.; Pichler, G.; Aziz, K.; Van Os, S.; O’Reilly, M.; Cheung, P.Y.; Schmölzer, G.M. Heart rate assessment immediately after birth. Neonatology 2016, 109, 130-138. [CrossRef] [PubMed]

48. Patel, S.; Cheung, P.-Y.; Solevåg, A.L.; Barrington, K.J.; Kamlin, C.O.F.; Davis, P.G.; Schmölzer, G.M. Pulseless electrical activity: A misdiagnosed entity during asphyxia in newborn infants? Arch. Dis. Child.-Fetal Neonatal Ed. 2018, 104, F215-F217. [CrossRef] [PubMed]

49. Luong, D.H.; Cheung, P.-Y.; O’Reilly, M.; Lee, T.-F.; Schmolzer, G.M. Electrocardiography vs. Auscultation to Assess Heart Rate During Cardiac Arrest With Pulseless Electrical Activity in Newborn Infants. Front. Pediatr. 2018, 6, 366. [CrossRef] [PubMed]

50. Luong, D.; Cheung, P.-Y.; Barrington, K.J.; Davis, P.G.; Unrau, J.; Dakshinamurti, S.; Schmölzer, G.M. Cardiac arrest with pulseless electrical activity rhythm in newborn infants: A case series. Arch. Dis. Child.-Fetal Neonatal Ed. 2019, 104, F572-F574. [CrossRef] [PubMed]

51. Sillers, L.; Handley, S.C.; James, J.R.; Foglia, E.E. Pulseless Electrical Activity Complicating Neonatal Resuscitation Established Facts. Neonatology 2019, 115, 95-98. [CrossRef]

52. Piastra, M.; Cavallaro, F.; Genovese, O.; De Luca, D.; Biasucci, D.G.; De Sanctis, R.; Pietrini, D.; Conti, G. Double cooling for pericardial tamponade and cardiac arrest after rewarming in neonatal asphyxia. Resuscitation 2013, 84, e83-e84. [CrossRef]

53. Hyde, P.; Puddy, V. Pulseless electrical activity after rapid administration of fresh frozen plasma. J. Paediatr. Child Health 2008, 44, 464-466. [CrossRef]

54. Kevat, A.C.; Bullen, D.V.R.; Davis, P.G.; Kamlin, C.O.F. A systematic review of novel technology for monitoring infant and newborn heart rate. Acta Paediatr. 2017, 106, 710-720. [CrossRef] [PubMed]

55. Dawson, J.A.; Schmölzer, G.M.; Wyllie, J. Monitoring heart rate in the delivery room. Semin. Fetal Neonatal Med. 2018, 23, 327-332. [CrossRef] [PubMed]

(C) 2020 by the authors. Licensee MDPI, Basel, Switzerland. This article is an open access article distributed under the terms and conditions of the Creative Commons Attribution (CC BY) license (http://creativecommons.org/licenses/by/4.0/). 